\title{
The Need for Involving Parents in the Rehabilitation of Persons with Special Needs in Nigeria
}

\begin{tabular}{l} 
Juliana Rotkangmwa Bodang ${ }^{1}$ (iD) \\
Rachael Asibi Amwe ${ }^{2}$ (D) \\
\hline${ }^{1,2}$ Department of Special Education and Rehabilitation Sciences, University of Jos, Nigeria \\
(\& Corresponding Author)
\end{tabular}

\begin{abstract}
The age long global trend of institutionalizing special needs persons/children for their rehabilitation is now being deemphasized in both the developed and the developing worlds. Emphasis is now shifted on the need for family and community involvement in the care and rehabilitation of children with disabilities. Thus, advocacy on the promotion of their well-being is now focused on community-based rehabilitation which many scholars consider as down to earth and more natural since the target population reside in their domain. Further, it entails the utilization of locally available resources to train special needs children/persons amongst varied communities. It is in this dimension that this paper discusses crucial issues such as what constitutes special children, their nature, needs as well as what constitutes specially in such children. In the same vein, the plight of the children in question has been highlighted bearing in mind socio-cultural practices, beliefs and attitudinal dispositions of the general populace as they pertain to parents/guardians of children with disabilities. Having clearly, highlighted the plight of special children in the Nigerian context, strategies to enhance their well-being as related to education, social as well as their economic aspect of life were also dwelt upon.
\end{abstract}

Keywords: Persons with special needs, Parents, Involvement, Need.

\section{Contents}

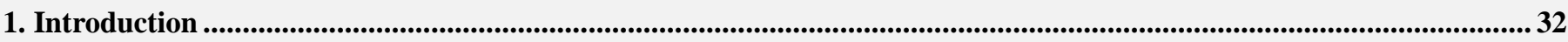

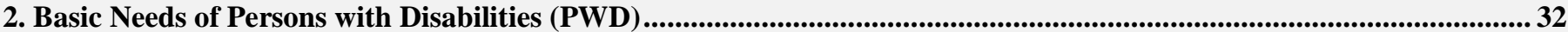

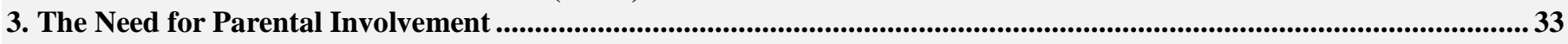

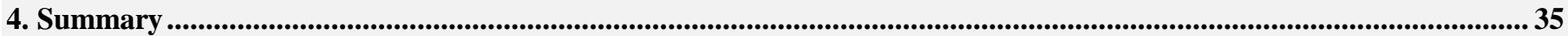

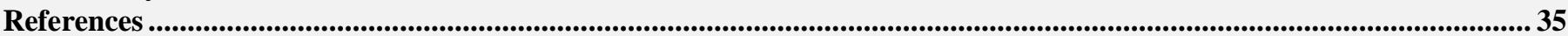

Citation | Juliana Rotkangmwa Bodang; Rachael Asibi Amwe (2017). The Need for Involving Parents in the Rehabilitation of Persons with Special Needs in Nigeria. Asian Journal of Social Sciences and Management Studies, 4(1): 31-35.

DOI:

$\operatorname{ISSN}(\mathbf{E})$

$\operatorname{ISSN}(\mathbf{P})$ :

Licensed:

Contribution

Funding:

Competing Interests:

Transparency:

History:

Ethical:

Publisher: 10.20448/journal.500/2017.4.1/500.1.31.35 Crossref

2313-7401

2518-0096

This work is licensed under a Creative Commons Attribution 3.0 License $(\mathrm{cc}) \mathrm{EY}$

All authors contributed to the conception and design of the study.

This study received no specific financial support.

The authors declare that they have no conflict of interests.

The authors confirm that the manuscript is an honest, accurate, and transparent account of the study was reported; that no vital features of the study have been omitted; and that any discrepancies from the study as planned have been explained. Received: 10 October 2016/ Revised: 1 December 2016/ Accepted: 8 December 2016/ Published: 15 December 2016 This study follows all ethical practices during writing.

Asian Online Journal Publishing Group 


\section{Introduction}

It is a well known fact that all children (whether normal or special) need to be taken care of, especially during the formative years which are the more crucial for any meaningful development in a child's life. As such, they need surveillance in order to develop their potentials to the maximum. Children need love and affection to develop a healthy physical and psychological being.

Special Needs Children (SNC) have been perceived as those whose performance in intellectual, physical, affective and psychomotor domain deviate significantly from the non-labeled /average (either above or below) to such extent that special education programming is needed, (Heward and Orlansky, 1984; Kirk and Gallagher, 1989; Lynn and Lewis, 1991).

Further, the same writers went on to classify special children as those who fall into one or more of the categories of those with mental retardation, learning disabilities, communication disorders, visual impairment, hearing impairment and those who are gifted and talented, i.e. children endowed with surplus cognitive ability in terms of extra-ordinary intelligence or those with potentials of being creative and original in their various endeavours. It is this which influences their thinking and learning as a result of which special modifications are employed to tap their potential which cannot be nurtured in the normal way. With the scope of special education receiving global attention, children in especially difficult circumstances like abandoned children, street children, children orphaned as a result of wars, land mines etc., have also been incorporated into the special needs children category. The mentioned children are seen as special or unique since they manifest special needs requiring modifications in various endeavours of life i.e. academic, social, physical aspects of life in order to enable them to function independently and to their maximum capacity in life.

Sometimes the special needs of such children manifest in a combination of inherent human characteristics as they relate their psychological, emotional and behavioural dispositions which in most instances aggravate the special needs of the children in question. As a result, living a normal life and benefit to the maximum becomes more difficult. Hence, modification of all their needs is imperative, before such children can achieve success in later life.

\section{Basic Needs of Persons with Disabilities (PWD)}

All humans generally have basic needs in their lives and existence. SNC are no exception, equally, they have basic needs which are unique or special in the sense that their critical life skills are often affected. It has been asserted that the developmental needs of SNC are usually compounded by their abilities and disabilities, Lynn and Lewis (1991).

Three basic needs have been identified: learning needs, Socio-emotional needs and physical and Health needs (Lynn and Lewis, 1991). Physical and health needs manifest essentially in terms of tendencies for compounded psychological and physical conditions normally occasioned by the disability which children with special needs have to live with. Such health conditions include internal diseases such as lung infections, kidney diseases, heart diseases etc. These may need constant health surveillance and monitoring of their health situation wherever they may be. Learning needs to manifest mainly in the form of poor cognitions and lack of adequate challenges to their cognitive capabilities. Invariably, formal learning in most instances could be problematic and the motivation for effective learning commensurate to their potential becomes a major need before any meaningful learning can be achieved.

Socio- economical needs refer to behavioural dispositions which constitute hindrance to effective adjustments required for daily living (Kolo, 1994). The satisfaction of those needs are directly responsible for the development of effective self-concepts, motivation and the zeal for effective adjustment. Satisfying socio-emotional needs also aid the development of children with disabilities to appreciate their own selves and others, and to develop healthy interpersonal relationship.

\subsection{Parentage of Special Needs Children in the Nigerian Environment}

Parenting a child is known and agreed to be carried on along a common pattern. Naturally, the arrival of a child into any family is met with merry-making and jubilation and is obviously known to be a tremendous responsibility. Invariably, parenting a SNC is known to be confronted with additional challenges as the arrival of such a child is greeted with shock, grief, sorrow, anxiety, etc. This is attributed to the fact that such parents are likely to be confused because of their limited ideas about how to accept and rear such a child. In a typical Nigeria setting, the child belongs not only to his biological parents but to all, most particularly those who reside in the same environment. As such, the joy or sorrow experienced with his/her arrival is obviously shared amongst family members, be it nucleus or extended.

Obviously, the parent now begin to think of what to do and how to rear the child in question by resorting to all possible solutions. Human nature being what it is, and due to individual differences, reactions vary from one individual parent to another (Turnbull and Turnbull, 1978). They now develop attitudes towards SNC which will have significant effect on the life of such children, be it in the short or long run (Ozoji, 1991). Ozoji (1999) maintained further that most problem Special Needs Populace encounter in their various context of life are basically attitudinal which is more of negative in nature. Summer (1994) identified the most common types of attitudes exhibited by most parents with SNC. These they maintained range from (i) acceptance of the child and his handicap in a desirable manner which easily enhances parental adjustment; (ii) denial; her, parents have the natural love in patients but cannot accept the disability in the children as real; (iii) over protectiveness- this attitude parents develop where SNC is hardly allowed to do anything by him/herself.

This has a very negative effect on the growing SNC since it is known to retard development physically, socially and mentally. This is attributed to the fact that such a child's initiatives are never allowed to develop neither is he/she encouraged to develop socially or mentally. In most instances, they live in an entirely different world which their parents decide for them. Invariably, this is known not to augur well for both the parents and the child in question, it harbours perpetual dependence. This attitude of over protectiveness is said to have bearing with common beliefs and 
socio-cultural practice in most Nigerian settings, where special needs populace are believed to be incapable of holding some parents develop which outwardly portrays them as willing to accept and aid their SNC but by their action it implies rejection of the child. The last of Summer\& Cohen attitude is that of open rejection of the child. The last of this attitude show nothing to their SNC other than hostility and outright rejection and neglect. Affection and appreciation of the worth in such children is virtually non-existent.

SNC based on the aforementioned discussion, regarding parenting special needs child in terms of his/her arrival, parental reaction and attitude patterns develop in the Nigerian context the child in question suffers in almost all context of life. This is to be extended beyond family/communal life. For he/he suffers necessarily and is said to have some religious bearing where a common belief exists that sins of parents are manifested in such children (Ozoji, 1994).

Hence, such parents suffers deflated egos, because the child who is an extension of themselves is less than perfect. Invariably, SNC are seen as victims and are made to suffer unnecessarily for what he/she is not a party to and not even aware of the handicap even though he/she may soon realize (depending on the degree and nature of his/her handicap (through treatment accorded by parents and other family members. Subsequently, the child feels unwanted, unloved and may eventually develop antisocial behaviours and delinquency. Hence, this brings about an urgent need for effective reorientation of parents and significant others for the betterment of SNC.

\section{The Need for Parental Involvement}

Parents everywhere are their children's first teachers. This fact is obvious and fundamental but in many cases this is not the case even in the pioneer countries notably UK and US who have advanced in the field of Special Education. Involvement of parents in the care and rehabilitation of SNC is a relatively new phenomenon. This is in the developing world where special education is still at its teething stage. In traditional Nigerian homes for instance, the care and rehabilitation of SNC is hardly regarded the responsibility of parents even though they spend substantial part of their time with them and nobody holds as much vested interest in the child.

The need for parental involvement in the care and rehabilitation of SNC cannot be over-emphasized. A child is said to need special care and attention for two reasons; either his/her problem which make special care imperative is congenital or adventitious: if it is congenital and the degree of severity of the problem has reached a level which makes independent living virtually impossible since birth, then he/she is in need of a form of education called habitation, which mainly focus on help skills. As for the adventitiously handicapped child, it extends beyond habitation to rehabilitation as to "restore". It is basically the process of enabling an individual to regain a number of skills that may have been lost through social, psychological or physical problem that the SNC had gone through. The non-involvement of parents in the rehabilitation of SNC in Nigeria can be drawn from the facts which clearly indicated that history has evidently shown that rehabilitation efforts in Nigeria, in most instances are inadequate, illplanned and ill-executed (Kolo, 1997). Hence, it is virtually impossible to achieve any remarkable or sustainable effort to ensure adequate rehabilitation programme, which in turn aid integration of the special needs populace into national life. Furthermore, rehabilitation in the Nigerian context have in most instances aided sufferings and untold misery on the special needs populace for, it is seen to promote more of segregation practice owing to 'exclusive isolation' in the centres. This again can be attributed to the prevalent superstitious beliefs and different negative interpretations that surround the birth of such children and that has led to rejectionist tendencies and many cases of outright termination of the lives of special needs population, particularly cases of mental retardation. More so, this has been the trend in most African settings.

Subsequently, rehabilitees in both Africa and Nigeria settings when they return to their families often become more stigmatised and are segregated the more from full societal life. Hence, this brings about the need for involvement of parents in the rehabilitation process of their special needs children. Their involvement will in no small measure reduce the double negative impacts on the growing child that he/she is made to go through. The child is made to lose parental care in their natural setting (home) and is made to undergo a regimented /routine life-style in a restricted environment (rehabilitation centre) which in most instances contribute in killing the potential/initiative they may be endowed with. To further buttress the strong need for parental involvement, it can be drawn from the experiences of the ill-fated 1970's rehabilitation scheme in eight centres across the country (Togonu-Bikersteth, 1996). This scheme has immensely encouraged segregation of special needs persons/children. Since its inception it become a breeding ground for dumping the target beneficiaries to "get treated in places meant for their like". As such, the centres turned to isolation sanctuaries for destitute where graduands are heavily stigmatised which in turn makes re-integration of rehabilitees into their respective families and societal life an awesome task. Invariably, due to the non-involvement of parents in the care of persons with special needs, many efforts hardly succeed in Nigeria. Even the traditional special schools that towed along rehabilitation did not fare any better in terms of enhancing their education and integration into national life. Eventually it aided outright rejection on the part of the target beneficiaries (Kolo, 1998).

Parents' involvement in the care and rehabilitation of persons with special needs if fully recognized and implemented will in many ways bail out the target beneficiaries out of their uncountable complications which are so entrenched in almost all facets of their lives like the scourge of destitution, beggary and idleness in which many of them have been involved. The parent will in no small measure ensure that the child in question is made to be aware and trained for needed skills acquisition which will in turn alert the child on the need to be useful to his/her self, family, community and the society at large. Hence, heavy dependence on beggary can be minimised or averted. Indeed with parental involvement, persons with special needs gets the necessary needed encouragement to develop a better self concept, i.e. appreciate and preserve the worth in himself/herself rather than resign to the fate which unfortunately has been the trend. As such the Persons with special needs in most instances do not regard him/her self as having any worth in his/her family, community and society with any definite or distinct role to play in later life. This, of course can be linked to ignorance on the part of some parents and the already emerging culture of beggary as a vocation exclusively meant for special needs persons. 
It is a well known and agreed fact that child-rearing from infancy through childhood to adolescence up to the time when a child becomes an actualised adult is very tedious and demanding on the part of parents. The same and even more for parents blessed with special needs child. Since they are special and unique in many respect in terms of their services, needs, facilities etc. Hence, in a bid to ease the tension and confusion mounted in such parents, the involvement of significant others will in some respect aid the onerous task of rearing a child who needs special attention.

\subsection{The Need for the Involvement of Significant Others}

Going by the saying of "everybody is his brother's keeper", the need to involve significant others in the care and rehabilitation of persons with special needs then is in order in the Nigerian context. The significant others comprise immediate family members and community members. In a typical Nigerian setting, the role of family members in the day-to-day running of any house is invaluable. since responsibilities are shared among family members, their involvement will aid the special needs person in the acquisition of some needed skills like getting to know house hold items, kitchen utensils, distinction of toilet area from the kitchen area, good toilet habits, getting to know other family members by name and gradually joining other family members in getting to know members outside the family circle i.e. peers and family members serve as role models. Hence, socialisation scope is being widened and the special needs person through interactions of this nature will get to acquire and learn to maintain adaptive behaviours and gradually begin to apply appropriate reasoning and judgment as well as mastery of the environment. Through involvement of peers, the child in question gets to acquire more social skills through participation in group activities as well as interpersonal relationships. Through involvement of family members, peers and community members the child with special needs get to imbibe the societal norms and values, respect the dignity and worth of others (Grossman, 1973).

Most importantly, community involvement represents a positive step forward, for it implies a total departure from the orthodox rehabilitation of special needs children/persons in residential institutions. With this development, responsibility of care and rehabilitation of the individual in need has been returned to his/her family and significant others (peers and community members). Hence, the individual with special need is trained in his/her immediate environment. He/she does not suffer unnecessarily, allowed to grow and develop physically/mentally in his natural domain, skills acquisition is easily facilitated, above all, fear of segregation and stigmatization is curtailed. subsequently, the special needs child will grow.

\subsection{Sustainable Strategies for Enhancing the Well-Being of the Persons with Special Needs in Nigeria}

For any strategy which is centered on human development to prosper or succeed, it entails effective commitment to ensure sustainability. Invariably, whatever strategy is designed towards the enhancement of the well-being of persons with special needs in the Nigerian context, it has to be that all are involved, acceptable to all and all encompassing. It is based on this guiding principle that a sustainable strategy can be drawn to foster his/her education, social and economic well-being.

In this context, first and foremost is the need for change of attitude. In a country like Nigeria where researchers have shown that attitude towards special needs populace is negative and rejectionist in nature, even on the part of parents blessed with special needs children. There has to be effective sensitization where by the parents of such children in particular and general population in general on the need for change of attitude towards persons with special needs and children. They have to be positively attitudinized. Parents and the general populace should learn to accept such a child no matter the nature of his/her disability, they should accept the child as somebody who is unique, capable of utilizing the potential in him/her to the maximum. Such a child needs to be shown love and affection. Parents should positively make the child to be aware of his/her disability and be encouraged to positively learn to utilize the strength he/she has to overcome weaknesses. This factor indeed is the most crucial, since parents are the principal caregivers of their offspring. When parents accept to positively treat their children with special needs then the other segments of the society will also change. Moreover, this positive change will go along to affect all other aspects that will have impact on the growing child later in life. That is, education, social and economic development.

Having positively attitudinized parents extensively, another major task is of the need of mass enlightenment, awareness programmes and education of parents on their special needs children. Such awareness programmes should be aimed at educating and making parents conscious of the fundamental human rights of the target beneficiaries (right to life, education and work) which if achieved, will form the basis of other human rights issues. A very viable strategy is the use of media using local language as a medium of communication. It is the easiest, cheapest and the quickest means of sending the message across to nooks and crannies of the country, particularly the rural areas where a good number of special needs children are found.

When parents are fully enlightened and made to be aware of the issues at stake they as well as the target beneficiaries will not wait for their rights to be extended as it is in most cases, they will strive for their rights. Transdisciplinary - inclusive approach entails the involvement of all related professionals in the habilitation and rehabilitation of special needs children/persons (Lynn and Lewis, 1991). This indeed, extends beyond the mainstream practices in the Nigerian context. These Persons with special needs are included in basically all aspects of national life. Closely linked with the factor is active participatory community involvement to ensure the full integration of persons with special needs into all aspects of national life where political commitment and involvement can be easily facilitated. These strategies when merged can ensure linkages which can make reach-out programmes accessible, most particularly at the grassroots level where this has continued to be a nagging problem. To achieve this, parents, community members, professionals, volunteers and representatives from the three tiers of government or even at Local Government level have to participate actively. In the educational context, target beneficiaries will acquire the needed skills for learning the basic pre-academic skills, numerical skills, identification 
of light vocabularies, be able to tell the time, day, name and parents, family members etc. On the economic terrain o national life, the target beneficiaries comes to learn some vocational skills of using the locally available resources in his/her community. These learnt skills will pave way for economic independence in later life. This is achievable by patronage of the finished products amongst his/her local community.

\section{Summary}

The paper however gave the general picture of special needs children, its highlights included their identified basic needs which range from learning, socio-economic as well as physical and health. Parental responsibility to special needs children in the Nigerian context was dwelt upon. Under this, the need for involvement of parents, significant others and community members in promoting the well-being of persons with special needs into all aspects of life in the terrain of national life was as well exhausted. To ensure this, sustainable strategies which if fully implemented will achieve much were drawn in the write - up. This is to ensure that Nigeria complies with the dictum that no society develops until everybody is educated to a level that contribution of members is enjoyed and children being leaders of tomorrow constitute an integral part of the development process.

\section{References}

Grossman, H.J., 1973. Manual on terminology and classification in mental retardation. Washington, D.C: AAMD.

Heward, N.L. and M.D. Orlansky, 1984. Exceptional children. Columbus, Ohio: Merrill.

Kirk, S.A. and J.J. Gallagher, 1989. Educating exceptional children. Boston: Houghton Mifflin.

Kolo, I.A., 1994. Elements education of special and remedial. An introduction text for students of special education. Jos: Deka Publications.

Kolo, I.A., 1997. An assessment of the UNDP assigned community based vocational rehabilitation schemes in Nigeria. Unpublished Paper Presented at the International Conference on Special Education, Federal College of Education (SP), Oyo Nigeria.

Kolo, I.A., 1998. Sustainable strategies for full integration of exceptional persons in Nigerian national life and development. Deka Special Education Monograph Series (4). Jos: Deka Associates.

Lynn, E.W. and R.B. Lewis, 1991. Exceptional children and adult. Glenview: Scott, Forssmann and Co.

Ozoji, E.D., 1991. Psychology of attitudes towards the disabled: The Nigerian perspective. Jos: Deka Publications.

Ozoji, E.D., 1994. Contemporary issues in special needs education. Jos: Deka Publications.

Ozoji, E.D., 1999. Selected issues in special education. Jos: Deka Publications.

Summer, V.A., 1994. The influence of parental attitudes and social environment on the personality development of the adolescence blind. New York: American Foundation for the Blind.

Togonu-Bikersteth, F., 1996. Impact of a community based vocational rehabilitation programme on self and others' perception of disabled persons. Life Psychologies: An International Journal, 4(1): 1-25.

Turnbull, A.P. and H.R. Turnbull, 1978. Parents speak out: Views from the other side of the two way mirror. Columbus, Ohio: Merrill. 